\title{
Epigenetic regulation of noncoding RNA transcription by mammalian RNA polymerase III
}

RNA polymerase III (Pol III) synthesizes a range of medium-sized noncoding RNAs (collectively 'Pol III genes') whose early established biological roles were so essential that they were considered 'housekeeping genes.' Besides these fundamental functions, diverse unconventional roles of mammalian Pol III genes have recently been recognized and their expression must be exquisitely controlled. In this review, we summarize the epigenetic regulation of Pol III genes by chromatin structure, histone modification and CPG DNA methylation. We also recapitulate the association between dysregulation of Pol III genes and diseases such as cancer and neurological disorders. Additionally, we will discuss why in-depth molecular studies of Pol III genes have not been attempted and how nc886, a Pol III gene, may resolve this issue.

First draft submitted: 22 August 2016; Accepted for publication: 3 November 2016; Published online: 18 January 2017

Keywords: epigenetic regulation • nc886 • RNA polymerase III

\section{RNA polymerase III}

For transcription of RNA from DNA, there are three RNA polymerases (Pol I, II and III) in eukaryotes (reviewed in [1]). Pol I transcribes all ribosomal RNA (rRNA) genes, except for $5 \mathrm{~S}$ rRNA. Pol II transcribes all protein-coding genes and some noncoding RNA (ncRNA) genes including long ncRNAs, many small nuclear RNAs (snRNAs) and miRNAs. Pol III transcribes a subset of ncRNAs (hereafter termed 'Pol III genes'), including tRNA, $5 \mathrm{~S}$ rRNA and U6 snRNA. Pol III is a well-characterized multisubunit enzyme complex (reviewed in [2]) and synthesizes various types of mediumsized ncRNAs that are 100-300 nucleotides (nts) long. Although we have used the term 'medium-sized' because short RNAs usually refer to a 20-nt length, such as miRNAs, Pol III is specialized for short-length transcription when compared with Pol I or II. In case of the transcription of miRNA genes, although their mature forms are short, Pol II actually transcribes long primary tran- scripts whose sizes are comparable to those of mRNAs.

Promoters of Pol III genes are classified into three types: type I (restricted to the $5 \mathrm{~S}$ rRNA gene), type II (typical of tRNA genes) and type III (for which the U6 snRNA promoter is paradigmatic; Figure 1). Each type has distinct promoter architecture and assembly steps of Pol III transcription factors (TFs). In all the three types, positioning of the catalytic Pol III enzyme complex at the transcription start site (TSS) needs TFIIIB consisting of BDP1 (B double prime 1), TBP (TATA-box binding protein) and BRF1 (B-related factor 1; for types I and II) or BRF2 (B-related factor 2; for type III). In the case of types I and II, TFIIIB is recruited by TFIIIC that recognizes the internal promoter elements box A and box B (or C in the case of type I). In type I, TFIIIA binding to the intermediate element should precede TFIIIC loading. In the case of type III, TFIIIB is recruited by the upstream promoter elements with the aid of SNAPc (small nuclear RNA
Jong-Lyul Park ${ }^{t, 1,2}$, Yeon-Su Lee $^{t, 3}$, Nawapol Kunkeaw ${ }^{4,5}$, Seon-Young Kim ${ }^{1,2}$, In-Hoo $\mathrm{Kim}^{6}$ \& Yong Sun Lee*,4,6 'Personalized Genomic Medicine Research Center, KRIBB,

Daejeon 305-806, Korea

2Department of Functional Genomics, University of Science \& Technology, Daejeon 305-806, Korea

${ }^{3}$ Cancer Genomics Branch, Research Institute, National Cancer Center, Goyang 10408, Korea

${ }^{4}$ Department of Biochemistry \& Molecular Biology, University of Texas Medical Branch, Galveston, TX 77555-1072, USA

Institute of Molecular Biosciences, Mahidol University, Nakhon Pathom, 73170, Thailand

${ }^{6} \mathrm{Graduate}$ School of Cancer Science \& Policy, National Cancer Center, Goyang 10408, Korea

*Author for correspondence:

Tel.: +1 4097722373

Fax: +1 4097728028

yslee@utmb.edu

${ }^{\dagger}$ Authors contributed equally
Future
Medicine fsg 


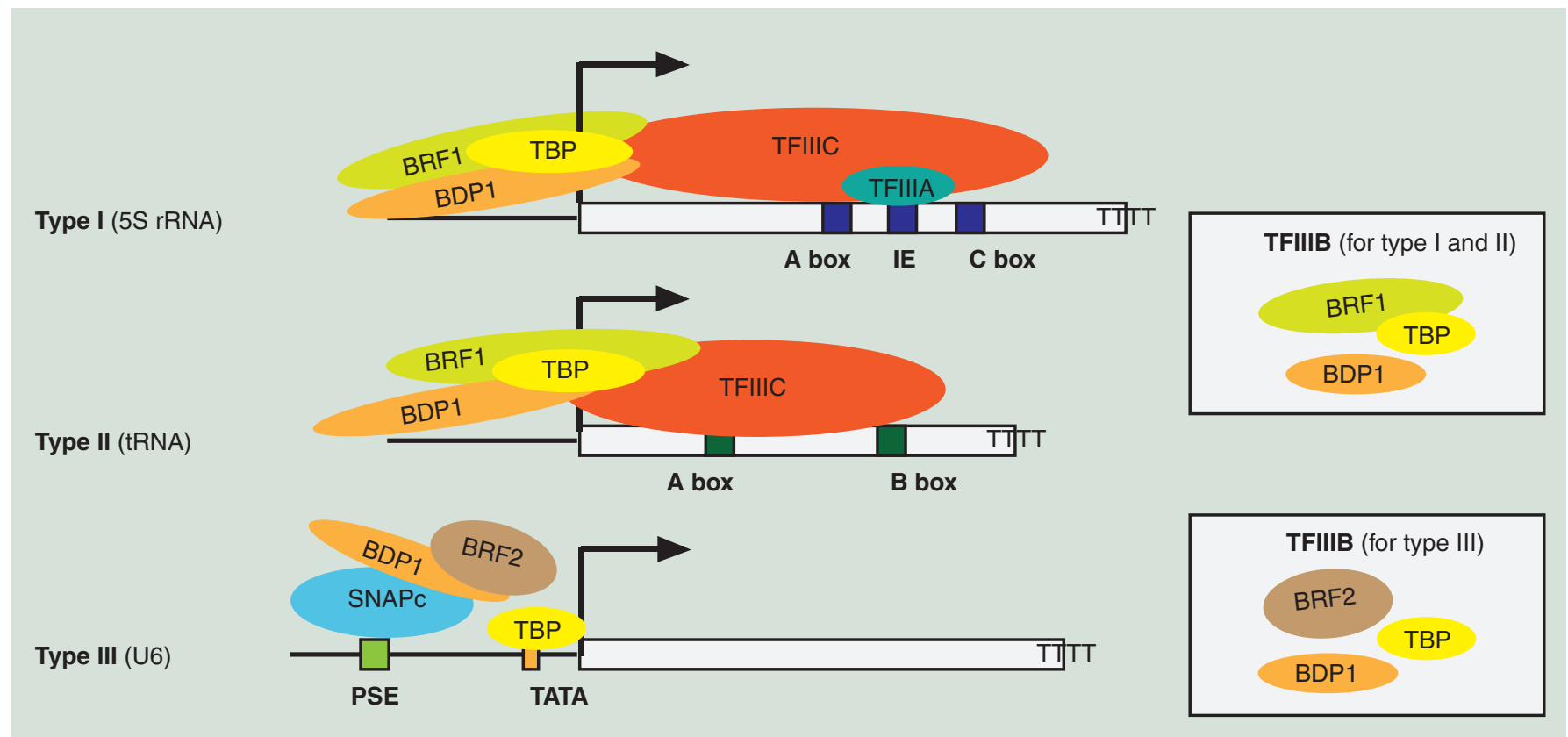

Figure 1. Three types of polymerase III promoters. A cartoon illustrating three Pol III promoter types. DNA sequence elements and protein factors are depicted. Arrows indicate a TSS and direction. 'TTTT' is the Pol III termination sequence. TFIIIB is the complex of three proteins and in the case of mammalian cells there are two different complexes with BRF1 or BRF2 (see boxes on the right). The relative positions of BRF1 and BDP1 are illustrated based on a ChIP-seq experiment in human cells [9]. BDP1 and BRF1 nearly coincide at approximately 20-nt upstream of TSS in the 5S rRNA gene (type I). In the case of tRNA genes (type II), BDP1 and BRF1 peaks are at -27 and -14 of TSS, respectively. Protein-protein interactions between TFIIIC and the three TFIII subunits have been reported and reflected in the cartoon (see [2] for details).

BDP: B Double Prime; BRF: B-Related Factor; ChIP: Chromatin immunoprecipitation; IE: Intermediate element; nt: Nucleotide; Pol III: Polymerase III; PSE: Proximal sequence element; TATA: TATA box; TF: Transcription factor; TSS: Transcription start site.

activating protein complex). Each Pol III promoter type and individual subunits of the Pol III machinery have been summarized in an excellent review [2] and are beyond the scope of this review. Therefore, we will not further elaborate on them, except that we intend to highlight different epigenetic regulations according to those Pol III types.

\section{Diverse roles of Pol III genes \& their regulation}

Many Pol III genes are abundantly expressed and were identified in early studies during 1970-1990. These classic Pol III genes include those coding for $5 \mathrm{~S}$ rRNA, tRNAs, some snRNAs (U6 type), 7SK RNA, 7SL RNA, BC200, vault RNAs (vtRNAs), Y RNA, RNase P RNA, RNase MRP RNA (reviewed in [3]). In general, they are a component of a ribonucleoprotein complex to serve as a catalytic core or a guiding molecule for sequence-specific nucleic acid metabolism, which plays roles in protein synthesis, RNA splicing, tRNA and rRNA processing, protein trafficking, DNA replication, etc. These processes are so vital that the classic Pol III genes were considered to be house-keeping genes and therefore Pol III regulation was rather understudied.
However, Pol III regulation is being recognized to be much more complicated especially in higher organisms. As opposed to yeast in which nearly all tRNA genes are actively transcribed [4-6], only a fraction of in silico predicted Pol III genes are occupied by the Pol III machinery and thus deemed to be active in mammalian cells [7-14]. Although the repertoire of active Pol III genes shows considerable overlap among cells of different tissue origins, cell-type specific Pol III-occupied loci do exist $[7,8,13]$. This observation indicates that a sophisticated regulatory mechanism for Pol III genes has emerged during evolution from simple eukaryotes to mammalian cells. Unlike Pol II genes, specific binding of TFs to upstream DNA sequences does not seem to be a prevailing mechanism to regulate individual Pol III genes. So, it has been speculated that epigenetic regulation could provide an alternative way [15]. Epigenetics is a broad term referring any inheritable trait caused by a change of genome functions that do not involve alteration of the DNA sequence. Variations in the chromatin structure caused by histone/DNA modification are the most common epigenetic mechanism and these will be discussed in this review. Results of studies from mammalian cells are mainly examined, but data from yeast (mostly 
Saccharomyces cerevisiae, studies about which are well summarized in an excellent review [15]) and amphibians (Xenopus laevis for early biochemical studies) will be also introduced when informative.

The Pol III transcriptome has been expanding [3] and a growing number of studies uncovered unconventional roles for classic Pol III genes (reviewed in [16]). For example, some tRNAs and vtRNAs are cleaved to produce small regulatory RNAs that play a miRNAlike function ([17], reviewed in [18]). Another example is vtRNA2-1 (a.k.a, nc886) that binds to Protein Kinase $\mathrm{R}$ (PKR) and suppresses its activity, rather than acting as a component of the vault complex [19]. Such new functions suggest that the roles of Pol III genes are diverse and that their expression needs to be exquisitely regulated in many biological situations via an epigenetic mechanism in concert with TFs that usually regulate general Pol III activity. Such examples include: alteration of Pol III activity by Rb, p53 and MYC (to be elaborated later), suppression of Pol III transcription by MAF1 under stress conditions (reviewed in [20]), elevation of tRNA expression in pathogen-stimulated macrophages through the NF- $\mathrm{kB}$ pathway [21], induction of Pol III transcription by alcohol via estrogen receptor- $\alpha$ [22] and decrease/increase in transcription of some Pol III genes, respectively, by tumor-suppressive/ stimulatory compounds $[23,24]$. In the last example, the chemical compounds (a polyphenol epigallocatechin gallate in [23] and a phytoestrogen in [24]) affected Pol III transcription interestingly in a gender-specific manner.

DNA methylation and histone modification are the most well-known mechanisms for gene silencing in mammalian cells. These epigenetic regulation mechanisms have been well studied in Pol II genes (reviewed in [25]), but not as extensively in Pol III transcription [15]. As mentioned above, classic Pol III genes are so essential that their silencing was beyond consideration. However, the uncovered diversity of Pol III genes and their biological roles suggests that epigenetic silencing is also important in some Pol III genes. One recent example is nc886 (a.k.a, vtRNA2-1) that is silenced by CpG DNA hypermethylation in several malignancies [26-29]. Besides cellular ncRNAs, Pol III transcribes some repeat elements, for example, short interspersed elements such as Alu and mammalianwide interspersed repeats, whose silencing is thought to be important in maintaining genomic integrity. Furthermore, some viruses employ the host Pol III to transcribe their ncRNAs, such as EBER1/2 and VAI, which suppress PKR as a mean to evade the host innate immune response. Silencing of those ncRNAs might be an important cellular mechanism to counteract viral infection.

\section{Dysregulation of Pol III genes \& diseases}

As listed above, Pol III genes play fundamental cellular roles as well as other diverse functions. Therefore, their expression should be tightly controlled, as evidenced by the fact that the failure of such regulation is implicated in a number of diseases including cancer and neurological disorders. Until recently, this alteration was only attributed to the deregulated activity of TFs or the malfunction of Pol III transcription and processing machinery, which will be summarized here (Table 1). Knowledge of Pol III regulation is essential to understanding these diseases and may be of future clinical value to prevent and/or to treat them.

\section{Cancer}

A hallmark of cancer cells is their increased growth rate that demands a higher rate of cellular metabolism. Since Pol III genes play fundamental roles in basic cellular metabolism, elevated Pol III transcription is expected and actually seen in transformed cell lines from a number of studies (see [30] and references therein). Expression of subunits of the Pol III machinery and Pol III genes has been found to be elevated also in clinical specimens; for example, TFIIIC2 in ovarian cancer [31], BRF1 in hepatocellular carcinoma [32], BRF2 in several malignancies including non-small-cell lung cancer and esophageal squamous cell cancer ([33-35], reviewed in [36]), tRNA expression in breast cancer [37], the expression of BC200 RNA, Y RNA and nc886 in several tumors [38,39]. Among these, nc886 deserves special attention as it is the only Pol III gene, thus far identified whose epigenetic regulation is implicated in malignancies. The cellular effects and regulation of nc886 will be elaborated upon later in a separate section.

Pol III activity is repressed by tumor suppressors such as $\mathrm{p} 53$ and $\mathrm{Rb}$, but is activated by oncogenes such as MYC. MYC is the most renowned oncogenic TF that amplifies the expression of a significant number ( $>15 \%$ of total) of genes when it is overexpressed in malignancies (reviewed in [40]). MYC activates the classic Pol III genes 5S rRNA and tRNA [41,42]. Rb and p53 are frequently inactivated in a number of malignancies (reviewed in [43]). The repression of Pol III transcription by $\mathrm{Rb}$ and $\mathrm{p} 53$ is well demonstrated in $R b$ - and $p 53$-knockout mice in which Pol III activity is elevated [44-47].

Rather than recognizing DNA sequence elements, MYC, $\mathrm{Rb}$ and $\mathrm{p} 53$ regulate Pol III transcription via their interaction with TFIIIB and thereby affect the subsequent steps of Pol III assembly [41,44-47]. Although this mechanism suggests that all Pol III genes should be similarly affected regardless of DNA sequence contexts, we speculate that epigenetic factors such as chro- 
Table 1. Disease associated with dysregulation of polymerase III genes and the polymerase III transcription/processing machinery.

\begin{tabular}{|c|c|c|c|c|}
\hline Gene & Description & Type of disease & Status & Ref. \\
\hline \multicolumn{5}{|c|}{ Dysregulation of Pol III genes and the Pol III transcription/processing machinery } \\
\hline TFIIIC2 & Pol III TF (a subunit of TFIIIC) & Cancer & Overexpressed & [31] \\
\hline BRF1 & Pol III TF (a subunit of TFIIIB) & Cancer & Overexpressed & [32] \\
\hline BRF2 & Pol III TF (a subunit of TFIIIB) & Cancer & Overexpressed & $\begin{array}{r}{[33-35],} \\
\text { reviewed } \\
\text { in [36] }\end{array}$ \\
\hline tRNA & Decoding mRNAs into proteins & Cancer & Overexpressed & [37] \\
\hline BC200 RNA & Translational modulator & Cancer & Overexpressed & [38] \\
\hline Y RNA & $\begin{array}{l}\text { Initiation of chromosomal DNA } \\
\text { replication }\end{array}$ & Cancer & Overexpressed & [39] \\
\hline MYC & Activation of Pol III transcription & Cancer & Overexpressed & $\begin{array}{r}\text { Reviewed } \\
\text { in [40] }\end{array}$ \\
\hline p53 & $\begin{array}{l}\text { Repression of Pol III } \\
\text { transcription }\end{array}$ & Cancer & Inactivated & $\begin{array}{r}\text { Reviewed } \\
\text { in [43] }\end{array}$ \\
\hline $\mathrm{Rb}$ & $\begin{array}{l}\text { Repression of Pol III } \\
\text { transcription }\end{array}$ & Cancer & Inactivated & $\begin{array}{r}\text { Reviewed } \\
\text { in [43] }\end{array}$ \\
\hline $\begin{array}{l}\text { POLR3A/ } \\
\text { POLR3B }\end{array}$ & $\begin{array}{l}\text { Subunits of the catalytic Pol III } \\
\text { complex }\end{array}$ & $\begin{array}{l}\text { Syndromic } \\
\text { hypemyelinating } \\
\text { leukodystrophies }\end{array}$ & Mutated & {$[48-50]$} \\
\hline POLR1C & $\begin{array}{l}\text { A subunit of both Pol I and Pol } \\
\text { III }\end{array}$ & Leukodystrophy & Mutated & [51] \\
\hline BRF1 & Pol III TF (a subunit of TFIIIB) & $\begin{array}{l}\text { Cerebellar-dental-skeletal } \\
\text { syndrome }\end{array}$ & Mutated & [52] \\
\hline$n-\operatorname{Tr} 20$ & A tRNA gene & Neurological defects & Mutated & [53] \\
\hline TSEN & tRNA-splicing endonuclease & $\mathrm{PCH}$ & Mutated & [54] \\
\hline CLP1 & $\begin{array}{l}\text { Maturation of tRNA and other } \\
\text { RNAs }\end{array}$ & $\begin{array}{l}\mathrm{PCH} \text {-like } \\
\text { neurodegeneration }\end{array}$ & Mutated & {$[55-57]$} \\
\hline BDP1 & Pol III TF (a subunit of TFIIIB) & $\begin{array}{l}\text { Nonsyndromic hereditary } \\
\text { hearing loss }\end{array}$ & Mutated & [58] \\
\hline RNase MRP & Mitochondrial RNA processing & Cartilage-hair hypoplasia & Mutated & [59] \\
\hline \multicolumn{5}{|c|}{ Dysregulation of Pol III genes by epigenetic mechanisms } \\
\hline nc886 & Suppression of PKR & Cancer & $\begin{array}{l}\text { Silenced by } \\
\text { CpG DNA } \\
\text { hypermethylation }\end{array}$ & [26-29] \\
\hline
\end{tabular}

matin structure and DNA methylation offer selectivity as a mechanism alternative to TF recognition of DNA sequence in the case of Pol II genes. For example, a subset of Pol III genes in heterochromatin might be excluded from MYC activation while all other Pol III genes are activated by MYC.

An outstanding question is whether the elevated Pol III activity in malignancies contributes to tumorigenesis. This elevated Pol III activity appears to be necessary to accommodate the increased cellular metabolism of cancer cells (reviewed in [36]). However, MYC, Rb and p53 also regulate multiple Pol II target genes and have a great impact upon cell physiology; thus, it is difficult to discern that portion of Pol III regulation from other indirect effects. Another problem in defining the role of Pol III deregulation in cancer is that MYC, Rb and p53 can regulate Pol III genes globally; so, it is challenging to pinpoint a specific individual Pol III gene. A recently identified Pol III gene, $n c 886$, is epigenetically silenced in cancer as opposed to most Pol 
III genes. This case will be extensively discussed later. Collectively, Pol III transcription is definitely altered in cancer; further studies will be needed to answer its exact role in tumorigenesis.

\section{Neurological disorders \& others}

POLR3A and POLR3B are subunits of the catalytic Pol III complex. Several studies have indicated that syndromic hypomyelinating leukodystrophies are caused in patients with mutations in POLR3A and POLR3B genes [48-50]. More recently, mutations in POLR1C, a common subunit of both Pol I and III, were detected in leukodystrophy patients. Those disease-associated mutations affect Pol III assembly and transcription, but not that of Pol I [51].

A cerebellar-dental-skeletal syndrome is caused by mutations in BRF1, a subunit of TFIIIB that loads Pol III to initiate transcription [52]. In this reference, the causal link was demonstrated unequivocally. Knockout of brfl in zebrafish results in similar neurodevelopmental defects that were corrected by the wildtype human BRF1 gene, but not by the mutant BRF1 harboring the syndrome-associated mutations.

Defects in proper expression and maturation of tRNAs have been implicated in neurological disorders. After transcription by Pol III, precursor tRNAs should undergo removal of the 5 '-leader and 3 '-trailer sequences as well as base modifications (reviewed in [18]). A mutation at the stem of the T-loop of a tRNA gene, $n$-Tr20 (a tRNA decoding the UCU anticodon to arginine), was identified in a mutagenesis screening of mice for neurological phenotypes. This mutation impairs the processing of the precursor tRNA and the consequent low level expression of the mature tRNA $n$-Tr20 is the cause of neurodegeneration phenotypes [53]. Some tRNA genes (6\% of the total tRNA genes in humans) have an intron, which should be removed by a tRNAsplicing endonuclease (TSEN). Inactivating mutations of TSEN have been identified in some subtypes of pontocerebellar hypoplasia [54]. A related observation is the mutations at CLP1, a multifunctional kinase implicated in the maturation of tRNAs and other RNAs in patients with neurodegeneration [55,56]. These mutations result in defective CLP1 lacking its kinase activity, leading to TSEN destabilization and consequently aberrant processing of tRNA [55-57].

Dysregulation of the Pol III machinery and Pol III genes is also causative to other diseases. A causative mutation for nonsyndromic hereditary hearing loss was identified at the $B D P 1$ gene encoding a subunit of TFIIIB [58]. RNase MRP RNA is a Pol III gene that plays multiple roles in mitochondrial DNA replication and pre-rRNA processing. Mutations at this gene are causative to cartilage-hair hypoplasia that is character- ized by short-limbed dwarfism due to skeletal dysplasia, variable level of immunodeficiency and predisposition to malignancies [59].

Collectively, several diseases are caused by alteration of Pol III transcription or dysregulation of the processing machinery as well as mutated Pol III genes. We anticipate that the repertoire of Pol III-associated diseases is more diverse than currently known and that more disease-causative alterations will be identified by virtue of cutting-edge technologies such as nextgeneration sequencing. However, the molecular link between Pol III genes and disease pathology remains unknown and its elucidation awaits future studies.

\section{Epigenetic regulation of Pol III genes: chromatin structure $\&$ histone modification}

The effect of chromatin status on Pol III transcription as well as its importance in Pol III gene regulation has been shown in many previous studies (see also [15], which is a comprehensive review on this topic). In general, compact chromatin is repressive to transcription. In the case of budding yeast, Pol III genes are localized in nucleosome-free regions ([60], see also [15] and references therein), in agreement with the fact that most tRNA genes are active. In contrast, the situation in mammalian cells appears to be complicated. Individual Pol III genes are localized in different chromatin milieu. The effect of chromatin structure is different in the three Pol III subtypes and is likely variable among individual Pol III genes. Rather than being passively subject to epigenetic regulation, Pol III transcription plays an active role in determining chromatin structure.

Histones are a principle component of chromatin, and their modifications are a key determinant of chromatin structure and therefore of gene expression. Methylation and acetylation are two major types of histone modification and these are diversified according to the specific lysine residues at which the modification occurs as well as to the number of methyl groups at a given lysine. Histone modification is well studied in Pol II genes, but much less so in Pol III genes [61].

\section{Compact chromatin is generally inhibitory to \\ Pol III transcription}

Typically, the assembly of chromatin structure onto naked DNA involves sequential binding of the histone $\mathrm{H} 3-\mathrm{H} 4$ tetramer and two histone $\mathrm{H} 2 \mathrm{~A}-\mathrm{H} 2 \mathrm{~B}$ dimers to form a histone octamer core particle. Then, the linker histone $\mathrm{H} 1$ is associated for chromatin compaction (reviewed in [62]). Early biochemical studies using yeast and Xenopus 5 S rRNA as a model Pol III gene indicated that transcription is generally less efficient on compact chromatin rather than on naked 
DNA [63-67] and that the repressive effect becomes greater as DNA/histones are assembled into more compact structures [67]. The histone octamer is more repressive than the $\mathrm{H} 3-\mathrm{H} 4$ tetramer [64,65]. $\mathrm{H} 1$ also directs further repression [68-72]. The repressive effect is more pronounced when the $5 \mathrm{~S}$ rRNA gene exists in multiple tandem copies, likely because an extended array of nucleosomes forms a more compact high-order structure [65].

These observations suggest that the inhibition of Pol III transcription may be simply a physical consequence of chromatin compaction. In this model (termed 'simple exclusion'), compact chromatin nonspecifically interferes with the binding of Pol III TFs or blocks the elongation of the polymerizing Pol III enzyme. Before making a general conclusion, it should be noted that $5 \mathrm{~S}$ rRNA is a type I promoter and does not represent all the Pol III genes. In the next section, we will introduce several cases of chromatin-mediated regulation to highlight the differences between individual Pol III genes, which cannot be well explained by a simple exclusion model.

\section{The effect of chromatin structure is more complicated than a simple exclusion model}

There are two types of Xenopus 5S rRNA genes oocyte and somatic. The effect of chromatin structure on these two types is different, although both are associated with histone octamers as well as the linker histone $\mathrm{H} 1$. The oocyte $5 \mathrm{~S}$ rRNA gene is inactive when placed into the context of somatic tissues, and this repression is dependent upon $\mathrm{H} 1$ [71,72]. In contrast, the somatic $5 \mathrm{~S}$ rRNA is active and unaffected by the binding of $\mathrm{H} 1[68-70,73,74]$. The explanation for this discrepancy between the two types includes differences in nucleosome organization [73], histone modification [75] and TF binding [70]. This phenomenon provides an interesting case of biological complexity, as the developmentally regulated expression of $5 \mathrm{~S}$ rRNA gene is quite surprising given that it plays a fundamental biological function and so is expected to be expressed constitutively.

Besides the switching of $5 \mathrm{~S}$ rRNA genes during development, the Alu repeat element is another intriguing example of chromatin-mediated regulation. Alu is present in more than 500,000 copies in the human genome, but is silenced in human cells in vivo, although it possesses Pol III promoter elements and is actually transcriptionally active in transfected cells and in vitro transcription assays. Certain biological conditions, such as adenovirus infection, relieve this suppression and robustly induce Alu transcription in vivo [76]. Alu is transcriptionally repressed upon nucleosome assembly in vitro with purified histones.
In this experimental condition, the repression does not require H1, unlike the case of 5S rRNA [66]. Recently, it has been shown that methylation at histone $\mathrm{H} 3$ is the underlying mechanism for the repression of Alu by compact chromatin structure [14].

The simple exclusion model predicts that chromatin compaction dominantly ejects the Pol III machinery from DNA. However, this seems to be largely incorrect. During the nucleosome assembly steps on the yeast and Xenopus $5 \mathrm{~S}$ rRNA gene, the histone octamer formation displaces TFIIIA when it alone is bound on DNA [64,65] (Figure 2). TFIIIA is the Pol III initiation factor specific to the type I $5 \mathrm{~S}$ rRNA gene and is required for subsequent recruitment of TFIIIC and then TFIIIB (Figure 1). Notably, once these TFs are assembled to form the complete Pol III machinery, transcription is resistant to the inhibition by the histone octamer [64,65] (Figure 2). Given that the transcription of the $5 \mathrm{~S}$ rRNA gene should be mostly in the active state, the observation raises the possibility that continuous active transcription cycles might not allow histones to exert a repressive effect in vivo.

In contrast to the $5 \mathrm{~S}$ rRNA gene that is repressed by compact chromatin unless TFIIIC is preloaded, tRNA genes are refractory to repression by histones [77] (Figure 2). tRNA is a type II gene and has internal promoter elements box $\mathrm{A}$ and box $\mathrm{B}$, which are recognized by TFIIIC. Upon DNA binding, TFIIIC recruits TFIIIB (Figure 1). So, unlike $5 \mathrm{~S}$ rRNA, it avoids the requirement of type I-specific TFIIIA that is evicted by histone octamers $[64,65]$. In a yeast study, nucleosome assembly was abrogated in a transcriptionally active tRNA gene; but it was resumed when a mutation was introduced at the promoter elements and thereby transcription was inactivated [77]. This observation corroborates the fact that most yeast tRNA genes are nucleosome-free and active [4-6,60]. Conceivably, transcription elongation may displace nucleosomes and thereby reverse the repression by compact chromatin. However, this simple mechanism is unlikely because TFIIIC plays an active role in remodeling chromatin assuring efficient transcription to occur, according to several reports on the yeast U6 snRNA gene (SNR6).

snRNAs are paradigmatic type III genes whose transcription is driven by external promoter elements including a TATA box (see Figure 1). The yeast snRNA SNR6 is an intriguing case. Unlike usual snRNA genes from other organisms, SNR6 has a box B sequence downstream of Pol III termination signal. This B box element is essential to transcription of chromatin templates (Figure 2), but is dispensable for naked DNA [78]. Actually, it has been well demonstrated that TFIIIC binding to the B box of SNR6 leads to chromatin remodeling in an ATP-dependent manner [79]. Notably, 
Type I (5S rRNA) partial assembly

Type I (5S rRNA)

Type II (tRNA)
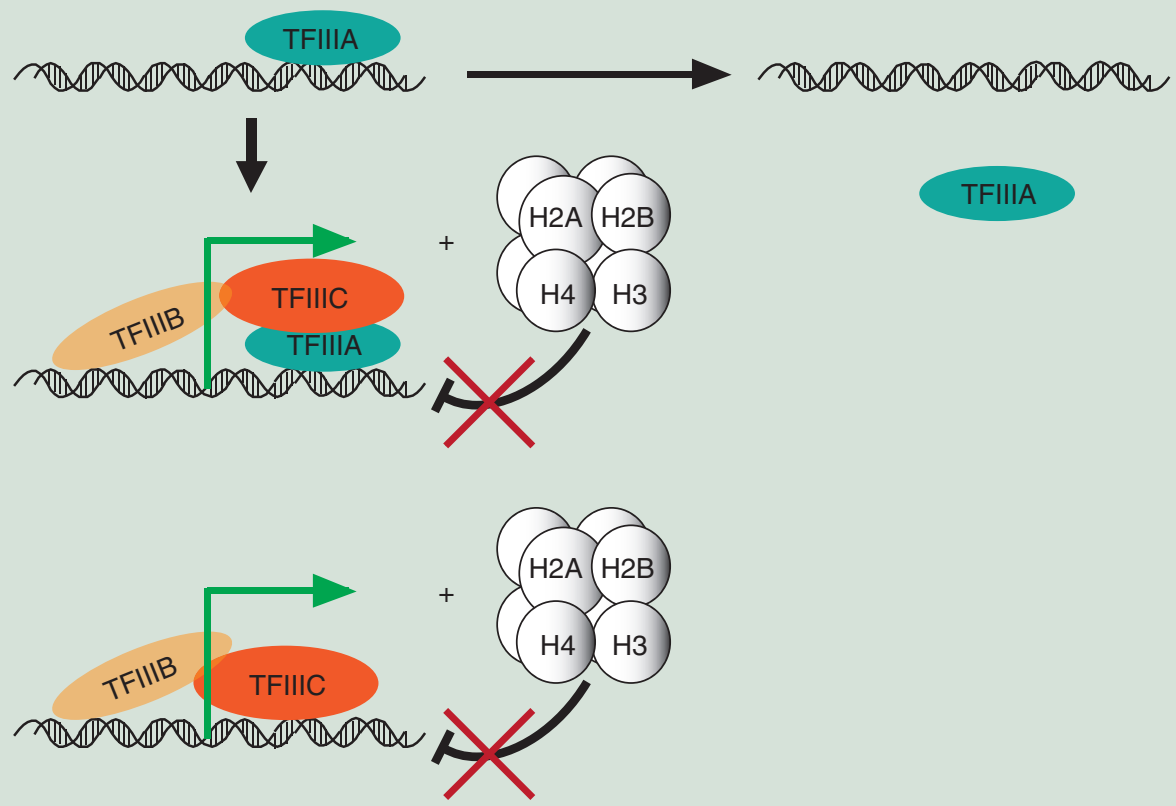

The role of TFIIIC in chromatin remodeling and its significance in Pol III transcription (yeast SNR6 gene)

In the absence of TFIIIC binding

TFIIIC binding to $B$ box

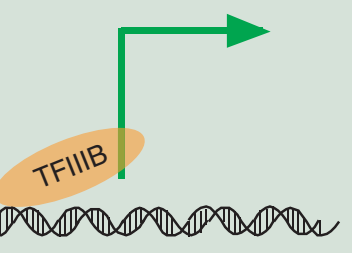

Naked DNA

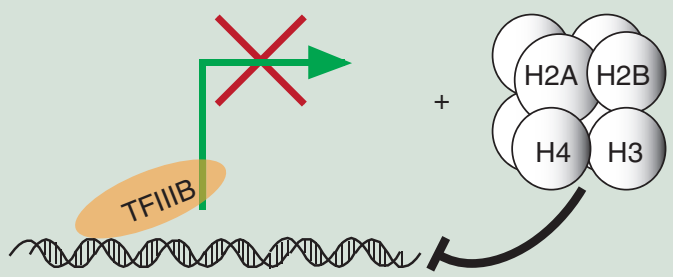

Chromatin

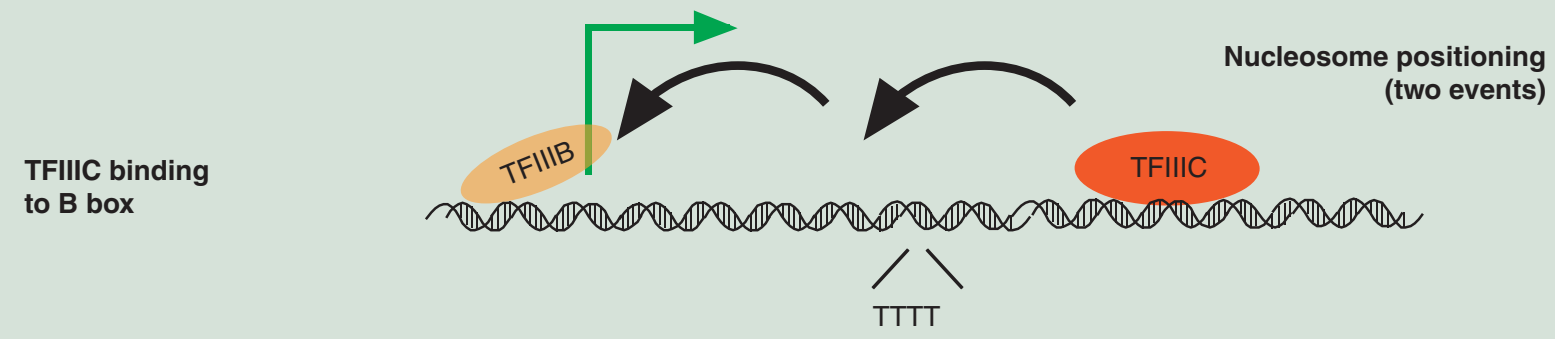

(Pol III termination signal)

Figure 2. Differential effect of histones on three polymerase III promoter types. (A) In the $5 \mathrm{~S}$ rRNA gene, the binding of histone octamers is dominant over TFIIIA before TFIIIC loading and displaces TFIIIA to inhibit transcription (the top image). In contrast, histone octamers cannot inhibit transcription after TFIIIC loading in the type I and type II Pol III promoters (2nd and 3rd images, respectively). See the text for details. (B) The role of TFIIIC in the case of the yeast SNR6 gene that harbors a TFIIIC-binding site (a box B) downstream of the Pol III termination signal. TFIIIC binding mediates two consecutive nucleosome positioning events for optimal binding of TFIIIB to ultimately activate transcription. See also the text for further details. SNR6: U6 snRNA; TF: Transcription factor. 
the TFIIIC effect is not simply to relieve the repressive effect of chromatin, because the transcription of the chromatin template in the presence of TFIIIC is more efficient than that of naked DNA. TFIIIC binding to the $\mathrm{B}$ box leads to a positioned nucleosome between the $\mathrm{A}$ and $\mathrm{B}$ boxes, which are consequently juxtaposed for the optimal binding of TFIIIC. Following this initial nucleosomal positioning, TFIIIC mediates another nucleosome re-arrangement by shifting the nucleosome between the boxes A and B to approximately 40 -nt upstream. This allows efficient loading of TFIIIB and ultimately high-level transcription [80]. In vivo probing of chromatin structure has indicated that the second rearrangement is critical for the modulation of SNR6 transcription under stress conditions [81]. These SNR6 data argue against the simple exclusion model by providing a remarkable example of the discriminating interplay between Pol III TFs and chromatin. It appears that TFIIIC plays a critical role in chromatin remodeling (Figure 2) and this will be discussed in the next section, in regard to its potential histone acetyltransferase (HAT) activity.

Collectively, the effect of chromatin structure on Pol III transcription seems to be very complicated. Chromatin structure has different effects on each Pol III promoter type (Figure 2) and is influenced by many other factors: DNA sequence contexts, the Pol III machinery and TFs. Early studies employed classic ncRNA genes that are transcribed from multiple genomic loci, leading to highly abundant and constitutive RNA expression. For those RNAs, what is the significance of regulation at individual loci? We hypothesize that an epigenetic change at a Pol III locus under some conditions might alter the expression of nearby Pol II genes by affecting the chromatin milieu. This hypothesis has been supported by several reports on yeast Pol III genes and one report on mouse short interspersed repeat elements (reviewed in [82]).

\section{A new era of Pol III study evolves due to advanced techniques}

Classic biochemical studies have been highly valuable to the initial understanding on epigenetic regulation of Pol III transcription. However, these studies were done in vitro and it was questionable whether the data reflect in vivo situations. This issue has been elucidated by advanced techniques. Chromatin immunoprecipitation (ChIP) assays are a commonly used method to assess the binding of the Pol III machinery in the original chromosomal context. One hurdle in studying Pol III regulation is the repetitive nature of many Pol III genes that makes it challenging to assess the contribution of each genomic locus among multiple genomic loci as well as to examine global Pol III expression pro- files. For this reason, ChIP of Pol III (Pol III enzyme or TFs recruiting it), which captures unique flanking sequences in addition to the transcripts themselves, is commonly used as a proxy indicator rather than the level of RNA. In yeast and Drosophila, ChIP in concert with array hybridization (ChIP-chip) defined the Pol III transcriptome mainly consisting of tRNA genes [4-6,83]. The advent of next-generation sequencing technologies provides a single nucleotide resolution and ChIP combined with this technique (ChIP-seq) has been exploited to identify the Pol III transcriptomes in mammalian cells.

Data from ChIP-seq of the Pol III machinery have provided an amazing wealth of information. Pol III ChIP-seq experiments have been done in several cancer cell lines, fibroblasts, stem cells, T-cells and mouse liver tissue ([7-14]; summarized in Table 2). These data clearly have proven that all Pol III genes are not active in mammalian cells and that they are expressed in a cell-type-specific manner. Pol III ChIP-seq captures some previously unidentified Pol III-bound loci and contributes to defining a complete Pol III transcriptome [7-11]. For example, nc886 was identified as a novel Pol III gene in this way [9,12]. It also confirmed the requirement of different Pol III TFs according to three promoter types (e.g., BRF1 for type I and II vs BRF2 for type III) in vivo [9]. Lastly, but most importantly, Pol III ChIP-seq data have been analyzed in comparison to genomic features (such as DNA sequence, histone marks, expression of nearby Pol II genes, the presence of $\mathrm{CpG}$ islands, etc.), providing insights about Pol III gene expression and regulation.

Several pieces of information from ChIP-seq data analysis are as followings. TFIIIC-occupied loci include but outnumber Pol III-occupied loci $[7,10,11,13]$, indicative of additional roles of TFIIIC besides Pol III transcription. In yeast, similar TFIIIC-only sites were identified and found to act as a barrier between hetero- and eu-chromatin [84]. Sequence comparison between Pol III-occupied or unoccupied tRNA genes indicates that the internal promoter elements boxes $\mathrm{A}$ and B share similar consensus sequences. So, promoter sequences, although they are required for transcription, do not appear to determine the expression level of tRNA genes [7,9]. ChIP-seq data have also shown a relation between global chromatin status and Pol III transcription. A remarkable case is the comparison of adipose-derived stem cells (ADSCs) to the ADSC-derived pluripotent stem cells [13]. ADSC-derived pluripotent stem cells are more pluripotent than ADSCs and also have Pol III binding at more loci, most likely because they have more open chromatin structure than ADSC. The relation to histone modifications and nearby Pol II genes will be discussed in the next section. 
Table 2. Summary of chromatin immunoprecipitation-seq experiments for polymerase III and modified histones.

\begin{tabular}{|c|c|c|c|}
\hline Cell lines or tissues & ChIP-seq with: & $\begin{array}{l}\text { Relation to histone modifications and } \\
\text { nearby Pol II (and brief description about } \\
\text { results) }\end{array}$ & Ref. \\
\hline $\begin{array}{l}\text { Human cell lines (HeLa, } \\
\text { HEK293T, human foreskin } \\
\text { fibroblasts, Jurkat) }\end{array}$ & $\begin{array}{l}\text { - TFIIIB (BRF1 and BRF2) } \\
\text { - TFIIIC (TFIIIC63) } \\
\text { - Pol III (RPC32) }\end{array}$ & $\begin{array}{l}\text { - H3K4me1/3, H2A.Z, H3K27ac } \\
\text { - H3K27me3 } \\
\text { - Pol II: (+) correlation to Pol III peaks } \\
\text { - DNase I hypersensitive sites: (+) } \\
\text { correlation to Pol III peaks }\end{array}$ & {$[7]$} \\
\hline $\begin{array}{l}\text { Human CD4 }{ }^{+} \mathrm{T} \text { cells (and } \\
\text { compared with HeLa) }\end{array}$ & $\begin{array}{l}\text { - TFIIIB (BRF1) } \\
\text { - TFIIIC (TFIIIC220) } \\
\text { - Pol III (RPC155) } \\
\text { - Pol II (S2P) } \\
\text { - H3K4me3 }\end{array}$ & $\begin{array}{l}\text { - H3K4me1/2/3, H2A.Z, H3K9ac, H3K4ac, } \\
\text { H3K23ac, H3K27ac, H3K36ac, H2AK9ac, } \\
\text { H3K18ac, H3K27me1, H4K16ac, H4K20me1 } \\
\text { - H3K27me2/3, H3K9me3 } \\
\text { - H3K79me2, H3K36me3 } \\
\text { - Pol II: (+) correlation to Pol III peaks }\end{array}$ & [8] \\
\hline IMR90hTert fibroblasts & $\begin{array}{l}\text { - TFIIIB (BDP1 and BRF1) } \\
\text { - SNAPC (SNAPC2) } \\
\text { - Pol III (RPC4) }\end{array}$ & No comparison & [9] \\
\hline $\begin{array}{l}\text { K562 (immortalized } \\
\text { myelogenous leukemia line) }\end{array}$ & $\begin{array}{l}\text { - TFIIIB (BDP1 and BRF1) } \\
\text { - TFIIIC (TFIIIC110) } \\
\text { - Pol III (RPC155) }\end{array}$ & $\begin{array}{l}\text { - H3K4me2/3, H3K27ac, H3K9ac } \\
\text { - Pol II: (+) correlation to Pol III peaks }\end{array}$ & [10] \\
\hline Mouse ES cells & $\begin{array}{l}\text { - TFIIIB (BRF1 and BRF2) } \\
\text { - TFIIIC (TFIIIC220/110/90) } \\
\text { - Pol III (RPC1/4) }\end{array}$ & No comparison & [11] \\
\hline Mouse liver tissue & $\begin{array}{l}\text { - Pol III (RPC1/4, RPB2) } \\
\text { - Pol II (RPB2) } \\
\text { - H3K4me3, H3K36me3 }\end{array}$ & $\begin{array}{l}-\mathrm{H} 3 \mathrm{~K} 4 \mathrm{me} 3 \\
-\mathrm{H} 3 \mathrm{~K} 36 \mathrm{me} 3\end{array}$ & [12] \\
\hline Human ES cells & $\begin{array}{l}\text { - TFIIIC (TFIIIC63) } \\
\text { - Pol III (RPC155) }\end{array}$ & $\begin{array}{l}\text { - H3K4me1/2/3, H2A.Z, H3K9ac, H3K27ac } \\
\text { - H3K36me3, } \\
\text { - H3K27me3 (cf. H3K27me3 in HeLa [8]) } \\
\text { - Pol II: (+) correlation to Pol III peaks }\end{array}$ & [13] \\
\hline HeLa cells and $\mathrm{A} 31$ fibroblasts & $\begin{array}{l}\text { - TFIIIB (BRF1) } \\
\text { - TFIIIC (TFIIIC110/220) } \\
\text { - Pol III (RPC155) } \\
\text { - H3K9me3 }\end{array}$ & $-\mathrm{H} 3 \mathrm{~K} 9 \mathrm{me} 3$ & [14] \\
\hline
\end{tabular}

Red- and blue-colored histone modifications indicate stimulatory and repressive functions to Pol III transcription.

BDP: B double prime; BRF: B-related factor; ChIP: Chromatin immunoprecipitation; ES: Embryonic stem; Pol: Polymerase; RPB: RNA

Polymerase II Subunit B; RPC: RNA Polymerase III Subunit C; SNAPC: Small nuclear RNA activating protein complex; TF: Transcription factor.

Histone acetylation

In general, histone acetylation is associated with open chromatin structure and active transcription [85]. For example, histone $\mathrm{H} 3$ acetylated at lysine residues 9 and 27 (H3K9ac and H3K27ac) is present at actively transcribed Pol II genes. Especially, H3K27ac is found in the enhancer region of Pol II genes. The positive effect of acetylation is similarly seen also in Pol III genes [75,86-88]. When acetylated in vitro, histone octamers lose their capability to interfere with TFIIIA binding to the Xenopus 5S rRNA gene [87], most probably because they become deficient in forming high-order structures [89]. A ChIP experiment revealed that acetylated histone $\mathrm{H} 4$ is associated with the transcriptionally active Xenopus somatic 5S rRNA gene [75], which corroborates aforementioned in vitro data. Recent mammalian ChIP-seq data are also in agreement with this concept. Pol III-occupied loci tend to be marked with $\mathrm{H} 3 \mathrm{~K} 9 \mathrm{ac}$ and H3K27ac ([7,8,10,13]; Figure 3A \& Table 2). Some acetylated histone marks display peaks relative to the TSS $[8,10]$. For example, H3K4ac, H3K9ac, H3K18ac are enriched at the -1 nucleosome of active Pol III genes (Figure 3A), suggesting that these histones contribute to defining the TSS of Pol III genes. Interestingly, these acetylated histones show peaks at the +1 nucleosome position in the case of Pol II genes. Other acetylated histones including $\mathrm{H} 2 \mathrm{AK} 9 \mathrm{ac}$ and $\mathrm{H} 4 \mathrm{~K} 16 \mathrm{ac}$ are enriched in 
active Pol III genes but no peaks are found near TSS. It should be noted in some mammalian ChIP-seq data that histones are depleted at the TSS $[8,10]$ similarly to yeast tRNAs [4-6], probably due to the fact that active transcription displaces nucleosomes [77].

So, how are the histones acetylated? As mentioned in the previous section, TFIIIC, a Pol III initiation factor composed of multiple subunits, can overcome nucleosome structure. TFIIIC was shown to possess intrinsic HAT activity in the 110 and $90 \mathrm{kDa}$ subunit (TFIIIC110 and TFIIIC90 in humans) [90,91]. However, a more recent study [92] indicated that TFIIIC has a very weak HAT activity as compared with p300, a potent HAT. When a Pol III gene in chromatin is transcribed in vitro with purified proteins, TFIIIC acts as a recruitment factor for $\mathrm{p} 300$ rather than as a bona fide HAT (Figure 3A). Nonetheless, TFIIIC may function as a HAT in vivo, possibly aided by some factors missing in the purified system. Another mechanism for histone acetylation is via MYC. Not only by interacting with TFIIIB, MYC activates Pol III transcription by acetylation. MYC recruits GCN5, a HAT, as well as the cofactor TRRAP at tRNA and $5 \mathrm{~S}$ rRNA genes (Figure 3A). This MYC-directed complex does not contain TIP60, although it is a HAT that acetylates histones in many Pol II genes [93]. As a result of p300 and GCN5 actions, histone $\mathrm{H} 3$ is hyperacetylated and Pol III recruitment is stimulated [88]. Based on a report [94], p300 and GCN5 are likely to be HATs for H3K27ac and H3K9ac, respectively (Figure $3 \mathrm{~A}$ ).

\section{Histone methylation}

Histone methylation is associated with either repressed or active chromatin [61]. Histone $\mathrm{H} 3$ trimethylated at lysine residues 9 and 27 ( $\mathrm{H} 3 \mathrm{~K} 9 \mathrm{me} 3$ and $\mathrm{H} 3 \mathrm{~K} 27 \mathrm{me} 3)$ is associated with repressive chromatin, whereas histone $\mathrm{H} 3$ that is mono-, di- or trimethylated at lysine residue $4(\mathrm{H} 3 \mathrm{~K} 4 \mathrm{mel} / 2 / 3)$ and is trimethylated at lysine 36 (H3K36me3) indicates open chromatin [95,96]. In the case of Pol II genes, H3K4mel is a marker for the enhancer region, $\mathrm{H} 3 \mathrm{~K} 4 \mathrm{me} 3$ is for active promoters and H3K36me3 is for transcription elongation.

Similarly to what has been observed in Pol II genes, Pol III ChIP-seq peaks are positively/negatively correlated with those open/repressive histone marks ([7,8,10-14]; Figure 3B \& Table 2). However, there are some differences between Pol II and Pol III genes. H3K4me3 displays a peak at the -1 nucleosome relative to TSS in Pol III genes, but at the +1 nucleosome in Pol II genes $[8,10,12]$. H3K27me3, as repressive chromatin mark, is enriched in both of inactive Pol II and Pol III genes. However, there is a sharp peak at the TSS in the case of Pol III genes (Figure 3B), but no peaks are seen in Pol II genes [8]. H3K79me2 and H3K36me3, which are present in active Pol II genes, are not enriched in active Pol III genes ([7,8,10,12,13]; Figure 3B). In the case of $\mathrm{H} 3 \mathrm{~K} 36 \mathrm{me} 3$, it can be explained by its methylation mechanism. The recruitment of a histone methyltransferase for H3K36me3, Set2, onto target chromatin is guided by its binding to the phosphorylated C-terminal domain tail of elongating Pol II [97]. This may be the reason for the lack of H3K36me3 in Pol III genes.

In the case of H3K27me3, its methylation appears to be executed by the histone methyltransferase EZH2, a component of the Polycomb repression complex 2 (PRC2) [98]. The recruitment of PRC2 to Pol III loci is mediated by physical interaction between PRC2 components (EZH2 itself and another component SUZ12) and TFIIIC subunits. This report again highlights the role of TFIIIC as a determinant for chromatin structure.

\section{Histone phosphorylation}

Besides histone acetylation and methylation, histone $\mathrm{H} 3$ is also phosphorylated at serine residues 28 and 10 (H3S28ph and H3S10ph) and this phosphorylation is implicated in mitotic chromosome condensation and regulation of gene expression (reviewed in [99]). A couple of reports have indicated the role of histone phosphorylation in Pol III transcription [100,101]. Treatment with an oncogene and a chemical carcinogen leads to the association of H3S28ph and H3S10ph with some Pol III loci to activate their transcription. This suggests that histone phosphorylation and the resultant activation of Pol III genes might contribute to the transformation process. However, the mechanistic link among histone phosphorylation, chromatin structure and Pol III transcription has not been explored and needs further investigation.

\section{Collaboration with neighboring Pol II genes}

Collectively, chromatin status dictated by histone modification is an important determinant for Pol III transcription. Therefore, it is not surprising that Pol II and Pol III genes are coregulated when closely located. This notion has been confirmed by comparisons between Pol II and Pol III ChIP-seq data. Pol II binding is enriched at approximately 300-nt upstream of U6 snRNA loci that are actively transcribed [102]. This close localization of Pol II is also seen in other Pol III genes including 7SK RNA, vtRNAs, RNase MRP RNA and many tRNA genes [8]. Several ChIP-seq data consistently indicated that Pol III occupancy is positively correlated with the active transcription of nearby Pol II genes $([7,8,10,12,13]$. Also, active Pol III loci have enriched Pol II binding ([7,8,10,13]; Table 2). 


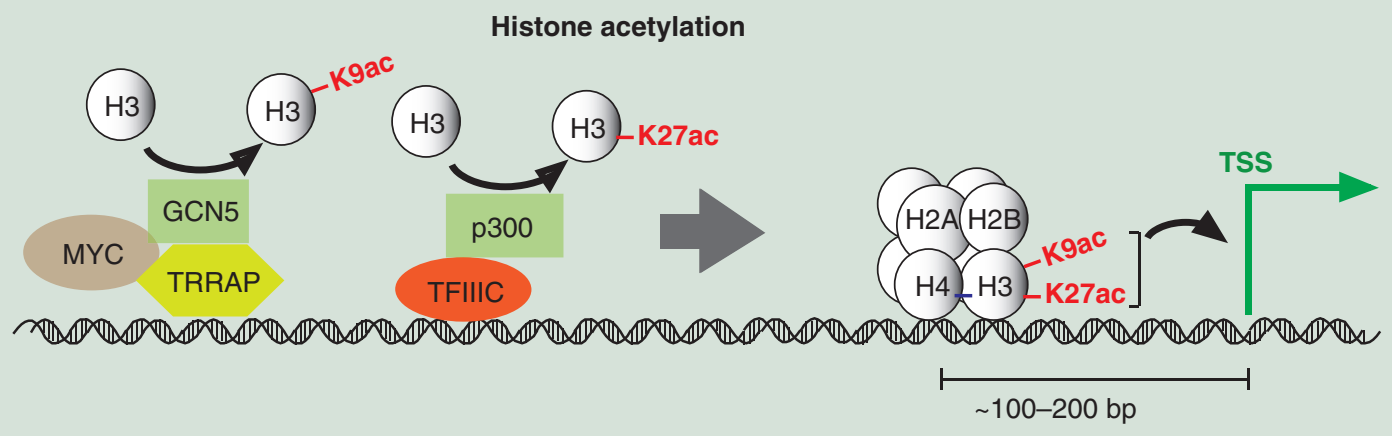

Histone methylation

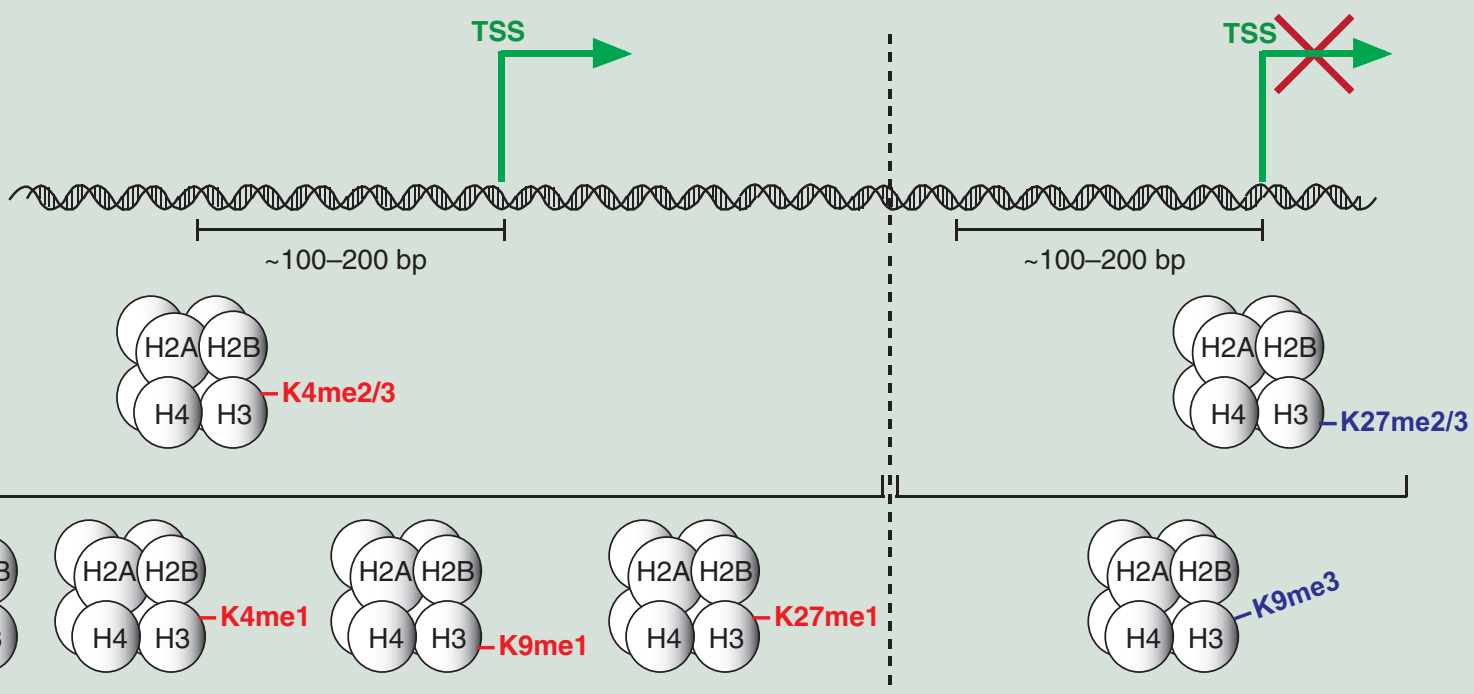

K20me1
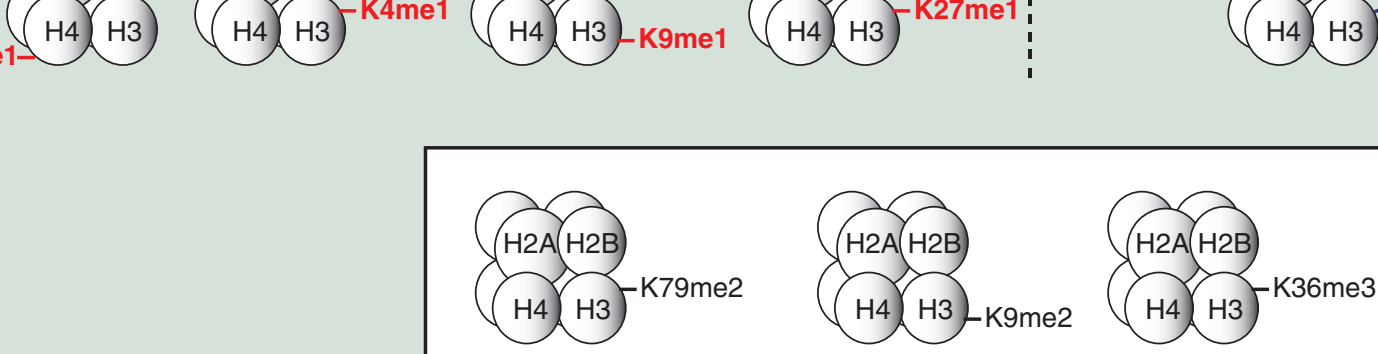

Figure 3. Summary of histone acetylation and methylation in polymerase III transcription. (A) Acetylation of histone H3. Histone H3 acetylation by GCN5 and p300 is shown on the left. The deposition of H3K9ac and H3K27ac at the indicated position relative to TSS stimulates Pol III transcription, as schematically shown on the right. See the text for details. (B) Roles of methylated histones in Pol III transcription. Red, blue and black letters indicate stimulatory, repressive and neutral methylation to Pol III transcription, respectively. $\mathrm{H} 3 \mathrm{~K} 4 \mathrm{me} 2 / 3$ and $\mathrm{H} 3 \mathrm{~K} 27 \mathrm{me} 2 / 3$ display a peak in indicated positions relative to TSS. Histones below horizontal brackets are enriched in the active/inactive Pol III loci, but display no prominent peak. Neutral histone marks are in a box below. See also Table 2.

GCN: General control of amino acid synthesis protein; Pol: Polymerase; TRRAP: Transformation/transcription domain-associated protein; TSS: Transcription start site.

\section{Epigenetic regulation of Pol III genes: CpG DNA methylation}

The most common epigenetic modification of DNA is methylation at the 5-carbon position of the pyrimidine ring of cytosine in $\mathrm{CpG}$ dinucleotides. Some gene promoters have a $\mathrm{CpG}$ island, a block of $\mathrm{CpG}$-rich sequences that is found at the promoter region of housekeeping genes or tumor-suppressor genes that are usu- ally unmethylated and expressed in normal conditions (reviewed in [103]). In some aberrant conditions such as malignant transformation, $\mathrm{CpG}$ hypermethylation occurs and the gene is silenced via chromatin remodeling (reviewed in [25]). This gene-silencing mechanism has been extensively studied in Pol II genes. In contrast, reports about CpG methylation and Pol III regulation are surprisingly scarce. 


\section{Early studies}

The first report of CpG DNA methylation was the measurement of Pol III transcription upon injection of in vitro methylated DNA templates into Xenopus oocytes [104]. Since then, similar experiments in mammalian cells and in vitro transcription assays have been performed in a handful of articles [26,27,105-107]. In general, Pol III transcription is inhibited by CpG methylation in these studies, but a couple of points should be addressed therein. First, the DNA templates were ectopically added and so might be considered in a nonchromosome context. However, they were expected to be in a chromatin context because they probably associated with histones soon after transfection into Xenopus oocytes, mammalian cells and in vitro transcription reactions employing crude extracts. Second, the three Pol III promoter types appear to be differently regulated: type II (for tRNAs) and type III (for U6 snRNA) were inhibited by methylation, whereas type I (for 5 S rRNA) was unaffected [104,108].

Silencing by $\mathrm{CpG}$ hypermethylation: what is the mechanism?

CpG DNA hypermethylation can lead to gene silencing via two possible mechanisms. One is the inhibition of Pol III accessibility through the remodeling of chromatin structure by histone modification ('indirect chromatin-remodeling mechanism'). This mechanism is well studied in Pol II genes (reviewed in [25]) and is presupposed to be true for Pol III genes. Actually, a number of ChIP-seq data have supported this model by showing that Pol III binding is positively correlated with histone markers for open chromatin and with the active transcription of neighboring genes [7,8,10-14]. However, this model is somewhat contradictory to data from the early studies that were discussed in the previous section. The indirect chromatin mechanism is hardly justified by the inefficient transcription from ectopically introduced CpG-methylated DNA templates. Moreover, if heterochromatin formation by hypermethylation is the simple mechanism, the three Pol III promoter types should be equally affected.

An alternative mechanism is that CpG hypermethylation per se renders the promoter less preferable for Pol III binding ('direct DNA-binding mechanism'). This model is favored by the aforementioned circumstantial evidence and also is directly supported by experimental data from an in vitro screening of proteins that bind to methylated DNA [109]. In this work, several proteins comprising TFIIIC bind efficiently to an unmethylated DNA fragment, but this binding is abrogated upon $\mathrm{CpG}$ methylation. Interestingly, the methylation effect on TFIIIC binding is seen in naked DNA, but disappears when the DNA is assembled into nucleosomes. In another study, $\mathrm{CpG}$ methylation inhibits binding of Pol III-activating TFs [106].

Further elucidation is needed as to which model is correct. Nonetheless, the two mechanisms are not necessarily mutually exclusive. Toward this goal, an in-depth mechanistic study is necessary, but such an investigation has been hampered by lack of a suitable model Pol III gene. Classic Pol III genes such as $5 \mathrm{~S}$ rRNA, tRNAs and U6 snRNA are not good models, because their transcription units are either identical or highly similar sequences that are scattered throughout the genome in multiple copies. Therefore, it is nearly impossible to correlate the transcription rate from a single genomic locus to the steady-state RNA level and also impractical to introduce a mutation into all genomic copies. Although some Pol III genes are encoded at a unique locus or a few loci, their silencing by CpG hypermethylation has not been reported until recently. In this regard, an interesting Pol III gene has been recently identified and will be discussed below.

nc886: a model Pol III gene that is epigenetically regulated by CpG methylation

As described in the previous section, some Pol III genes were shown to be suppressed by CpG DNA methylation. However, the biological significance is obscure in most cases. nc886 is the first and so far only Pol III gene which is silenced by CpG DNA hypermethylation and some functions in disease have been identified [26-29].

nc886, a 101-nt long ncRNA, was originally known as a precursor miRNA or a vtRNA. Actually, it was registered in the miRNA database (miRBase; www.mirbase.org/). Additionally, VTRNA2-1 is listed as the official name (in HUGO Gene Nomenclature Committee; http://www.genenames.org/), because nc886 shows considerable sequence homology to canonical vtRNAs that are RNA components of a large ribonucleoprotein complex called the vault complex. However, strong experimental evidence has demonstrated that nc886 neither produces mature miRNAs nor exists in the vault complex [19]. The same report discovered that nc886 binds to a protein called PKR that plays critical biological roles in innate immunity and cancer (reviewed in [110]). Upon binding, nc886 suppresses PKR activity. Epigenetic silencing of nc886 during tumorigenesis leads to PKR activation that appears to serve as an intrinsic pro-inflammatory signal to provoke oncogenes. So, nc886 is a putative tumor suppressor.

nc886 has a strong $\mathrm{CpG}$ island at its upstream region. Among the three Pol III promoter types, nc886 seems to belong to type II because it has the well-conserved internal promoter elements boxes $\mathrm{A}$ and $\mathrm{B}$, which are recognized by TFIIIC and so is crucial for transcription 
[Lee YS, Unpublished Data; see also (Figure 1)]. The nc886 $\mathrm{CpG}$ island encroaches into the transcribed region and encompasses boxes $\mathrm{A}$ and $\mathrm{B}$. Interestingly, each box contains a $\mathrm{CpG}$ dinucleotide. In nc886 and any other Pol III genes, it is completely unexplored whether $\mathrm{CpG}$ methylation on these residues is necessary and/or sufficient to interfere with TFIIIC recognition. Such a study might provide a clue to discern between the two mechanisms: 'indirect chromatin-remodeling mechanism' versus 'direct DNA-binding mechanism.'

\section{The significance of nc886 silencing in}

\section{malignancies \& other diseases}

Clinical data in gastric cancer, esophageal squamous cell carcinoma, small cell lung cancer and acute myeloid leukemia strongly supported the idea that nc886 is a tumor suppressor. In these malignancies, $\mathrm{CpG}$ hypermethylation of nc886 is associated with poor survival of patients [26-29]. It should be underscored again that such epigenetic silencing of a Pol III gene in malignancies was unprecedented until the identification of nc886. nc886's role in cancer is well summarized in a recent review [111].

Besides its silencing in cancer, the methylation of nc886 has several uniquely intriguing aspects. In normal human individuals, it is methylated in one allele, specifically of maternal origin $[28,112]$. Also, it is a metastable epiallele whose degree of methylation in the offspring is determined by maternal nutrient status during the periconceptional period [113]. Given that nc886 suppresses PKR, the variable expression of nc886 according to the degree of methylation is expected to determine an individual's differential response to inflammatory signals and thus susceptibility to viral infection. So, nc886 is hypothesized to be implicated in infection-related diseases, but this awaits further investigation. Apart from the biological consequence, those observations on nc886 are also scientifically interesting by themselves and raise several questions. How does maternal diet influence offspring's methylation status? When the maternal allele is methylated during early development, how does the methylation machinery distinguish it from the other alleles and specifically methylate it? Is the molecular mechanism of methylation (i.e., methylation enzymes) different between the normal developmental program and tumorigenesis?

\section{Future perspective}

Classic biochemical studies laid the foundation of our knowledge on epigenetic regulation of Pol III transcription. Following this, recent genome-wide studies are providing ample information in an unprecedented way. Now, we appreciate that detailed regulatory mechanisms for individual Pol III genes seem to be much more complex than has been previously thought. We anticipate that accumulation of global ChIP-seq and RNA-seq data will be instrumental in elucidating how individual genes are epigenetically regulated. However, this should be complemented by in-depth molecular studies that have fallen behind because of lack of a suitable model Pol III gene. Toward this goal, nc886 could be an ideal Pol III gene to investigate molecular mechanisms, because it is encoded at a unique locus in the human chromosome unlike many repetitive

\section{Executive summary}

Background of RNA polymerase III

- Polymerase III (Pol III) transcribes medium-sized noncoding RNAs (Pol III genes) with fundamental and also diverses unconventional cellular functions.

- Pol III genes are tightly controlled via epigenetic mechanisms.

Deregulation of Pol III genes \& diseases

- Pol III expression is elevated in cancer. In this case, MYC, Rb and p53 regulate the Pol III machinery to alter Pol III genes globally.

- Mutations in genes coding the Pol III polymerase and processing enzymes are causative to some neurological disorders.

- Epigenetic silencing of nc886 plays a role in tumorigenesis and hypothetically in infection-related diseases.

Epigenetic regulation of Pol III genes: chromatin structure \& histone modification

- Compact chromatin is generally repressive in Pol III transcription; however, its effects on individual Pol III genes are diverse and furthermore, it is in turn influenced by the Pol III machinery.

- Pol III transcription is activated and repressed by histone modifications indicative of open chromatin and heterochromatin, respectively. Consistently, Pol III transcription is positively influenced by active transcription of nearby Pol Il genes.

Epigenetic regulation of Pol III genes: CpG DNA methylation

- CpG methylation appears to differently affect three subtypes of Pol III genes.

- The suppression of Pol III genes by CPG hypermethylation involves heterochromatin formation; however, its direct effect on the Pol III machinery to bind to promoter sequences is also a possibility.

- A Pol III gene called nc886 has been recently found to be silenced by CpG hypermethylation. 
Pol III genes and so is experimentally manageable in vivo. Investigation of a model for Pol III transcription will certainly provide useful information in studying other Pol III genes, even though nc886's molecular mechanism would probably not represent all Pol III genes because epigenetic regulation of individual Pol III genes is extremely diverse as has been emphasized throughout this review. Finally, we expect that more cases of Pol III genes will be identified as being epigenetically regulated in various biological conditions, such as differentiation, human diseases, virus infection and malignancies.

\section{Acknowledgements}

The authors thank BH Johnson for critical reading of this manuscript and English editing.

\section{References}

Papers of special note have been highlighted as:

- of interest; $\bullet$ of considerable interest

1 Cramer P, Armache KJ, Baumli S et al. Structure of eukaryotic RNA polymerases. Ann. Rev. Biophys. 37, 337-352 (2008).

2 Schramm L, Hernandez N. Recruitment of RNA polymerase III to its target promoters. Genes Dev. 16(20), 2593-2620 (2002).

3 Dieci G, Fiorino G, Castelnuovo M, Teichmann M, Pagano A. The expanding RNA polymerase III transcriptome. Trends Genet. 23(12), 614-622 (2007).

4 Harismendy O, Gendrel CG, Soularue P et al. Genomewide location of yeast RNA polymerase III transcription machinery. EMBO J. 22(18), 4738-4747 (2003).

5 Roberts DN, Stewart AJ, Huff JT, Cairns BR. The RNA polymerase III transcriptome revealed by genome-wide localization and activity-occupancy relationships. Proc. Natl Acad. Sci. USA 100(25), 14695-14700 (2003).

6 Moqtaderi Z, Struhl K. Genome-wide occupancy profile of the RNA polymerase III machinery in Saccharomyces cerevisiae reveals loci with incomplete transcription complexes. Mol. Cell. Biol. 24(10), 4118-4127 (2004).

7 Oler AJ, Alla RK, Roberts DN et al. Human RNA polymerase III transcriptomes and relationships to Pol II promoter chromatin and enhancer-binding factors. Nat. Struct. Mol. Biol. 17(5), 620-628 (2010).

-• Provides a comprehensibly curated list of the human Pol III transcriptome.

8 Barski A, Chepelev I, Liko D et al. Pol II and its associated epigenetic marks are present at Pol III-transcribed noncoding RNA genes. Nat. Struct. Mol. Biol. 17(5), 629-634 (2010).

-• Comprehensively analyzing Pol III occupancy in relation to histone modification.

9 Canella D, Praz V, Reina JH, Cousin P, Hernandez N. Defining the RNA polymerase III transcriptome: genome-wide localization of the RNA polymerase III transcription machinery in human cells. Genome Res. 20(6), 710-721 (2010).

\section{Financial \& competing interests disclosure}

This work was supported by a Research Scholar Grant, RSG12-187-01 - RMC from the American Cancer Society to YS Lee, research grant no. 1610090 from the National Cancer Center to Y-S Lee. The authors have no other relevant affiliations or financial involvement with any organization or entity with a financial interest in or financial conflict with the subject matter or materials discussed in the manuscript apart from those disclosed.

No writing assistance was utilized in the production of this manuscript.

\section{Open access}

This work is licensed under the Attribution-NonCommercialNoDerivatives 4.0 Unported License. To view a copy of this license, visit http://creativecommons.org/licenses/by-nc-nd/4.0/

10 Moqtaderi Z, Wang J, Raha D et al. Genomic binding profiles of functionally distinct RNA polymerase III transcription complexes in human cells. Nat. Struct. Mol. Biol. 17(5), 635-640 (2010).

11 Carriere L, Graziani S, Alibert $\mathrm{O}$ et al. Genomic binding of Pol III transcription machinery and relationship with TFIIS transcription factor distribution in mouse embryonic stem cells. Nucleic Acids Res. 40(1), 270-283 (2012).

12 Canella D, Bernasconi D, Gilardi F et al. A multiplicity of factors contributes to selective RNA polymerase III occupancy of a subset of RNA polymerase III genes in mouse liver. Genome Res. 22(4), 666-680 (2012).

13 Alla RK, Cairns BR. RNA polymerase III transcriptomes in human embryonic stem cells and induced pluripotent stem cells, and relationships with pluripotency transcription factors. PLoS ONE 9(1), e85648 (2014).

14 Varshney D, Vavrova-Anderson J, Oler AJ, Cowling VH, Cairns BR, White RJ. SINE transcription by RNA polymerase III is suppressed by histone methylation but not by DNA methylation. Nat. Commun. 6, 6569 (2015).

15 Bhargava P. Epigenetic regulation of transcription by RNA polymerase III. Biochim. Biophys. Acta 1829(10), 1015-1025 (2013).

16 Hu S, Wu J, Chen L, Shan G. Signals from noncoding RNAs: unconventional roles for conventional pol III transcripts. Int. J. Biochem. Cell Biol. 44(11), 1847-1851 (2012)

17 Persson H, Kvist A, Vallon-Christersson J, Medstrand P, Borg A, Rovira C. The non-coding RNA of the multidrug resistance-linked vault particle encodes multiple regulatory small RNAs. Nat. Cell Biol. 11(10), 1268-1271 (2009).

18 Fu Y, Lee I, Lee YS, Bao X. Small non-coding transfer RNAderived RNA fragments (tRFs): their biogenesis, function and implication in human diseases. Genomics \& Informatics 13(4), 94-101 (2015).

19 Lee K, Kunkeaw N, Jeon SH et al. Precursor miR-886, a novel noncoding RNA repressed in cancer, associates with PKR and modulates its activity. RNA 17(6), 1076-1089 (2011). 
- The first identification of nc886.

20 Khanna A, Pradhan A, Curran SP. Emerging roles for Maf1 beyond the regulation of RNA polymerase III activity. J. Mol. Biol. 427(16), 2577-2585 (2015).

21 Graczyk D, White RJ, Ryan KM. Involvement of RNA polymerase III in immune responses. Mol. Cell. Biol. 35(10), 1848-1859 (2015).

22 Zhang Q, Jin J, Zhong Q, Yu X, Levy D, Zhong S. ERalpha mediates alcohol-induced deregulation of Pol III genes in breast cancer cells. Carcinogenesis 34(1), 28-37 (2013).

23 Diette N, Koo J, Cabarcas-Petroski S, Schramm L. Gender specific differences in RNA polymerase III transcription. J. Carcinog. Mutagen. 7(1), pii: 251 (2016).

24 Koo J, Cabarcas-Petroski S, Petrie JL, Diette N, White RJ, Schramm L. Induction of proto-oncogene BRF2 in breast cancer cells by the dietary soybean isoflavone daidzein. $B M C$ Cancer 15, 905 (2015).

25 Fuks F. DNA methylation and histone modifications: teaming up to silence genes. Curr. Opin. Genet. Dev. 15(5), 490-495 (2005).

26 Lee KS, Park JL, Lee K et al. nc886, a non-coding RNA of anti-proliferative role, is suppressed by CpG DNA methylation in human gastric cancer. Oncotarget 5(11), 3944-3955 (2014).

27 Lee HS, Lee K, Jang HJ et al. Epigenetic silencing of the non-coding RNA nc886 provokes oncogenes during human esophageal tumorigenesis. Oncotarget 5(11), 3472-3481 (2014).

28 Treppendahl MB, Qiu X, Sogaard A et al. Allelic methylation levels of the noncoding VTRNA2-1 located on chromosome 5q31.1 predict outcome in AML. Blood 119(1), 206-216 (2012).

-. The first report on CpG methylation-mediated dysregulation of a Pol III gene in a disease.

29 Cao J, Song Y, Bi N et al. DNA methylation-mediated repression of miR-886-3p predicts poor outcome of human small cell lung cancer. Cancer Res. 73(11), 3326-3335 (2013).

30 White RJ. RNA polymerase III transcription and cancer. Oncogene 23(18), 3208-3216 (2004).

31 Winter AG, Sourvinos G, Allison SJ et al. RNA polymerase III transcription factor TFIIIC2 is overexpressed in ovarian tumors. Proc. Natl Acad. Sci. USA 97(23), 12619-12624 (2000).

32 Zhong Q, Xi S, Liang J et al. The significance of BRF1 overexpression in human hepatocellular carcinoma. Oncotarget 7(5), 6243-6254 (2016).

33 Lu M, Tian H, Yue W et al. TFIIB-related factor 2 over expression is a prognosis marker for early-stage non-small cell lung cancer correlated with tumor angiogenesis. PLoS ONE 9(2), e88032 (2014).

34 Tian Y, Lu M, Yue W et al. TFIIB-related factor 2 is associated with poor prognosis of nonsmall cell lung cancer patients through promoting tumor epithelialmesenchymal transition. Biomed. Res. Int. 2014, 530786 (2014).
35 Lu M, Tian H, Yue W et al. Overexpression of TFIIB-related factor 2 is significantly correlated with tumor angiogenesis and poor survival in patients with esophageal squamous cell cancer. Med. Oncol. 30 (2), 553 (2013).

36 Cabarcas S, Schramm L. RNA polymerase III transcription in cancer: the BRF2 connection. Mol. Cancer 10, 47 (2011).

37 Pavon-Eternod M, Gomes S, Geslain R, Dai Q, Rosner MR, Pan T. tRNA over-expression in breast cancer and functional consequences. Nucleic Acids Res. 37(21), 7268-7280 (2009).

38 Chen W, Bocker W, Brosius J, Tiedge H. Expression of neural BC200 RNA in human tumours. J. Pathol. 183(3), 345-351 (1997).

39 Christov CP, Trivier E, Krude T. Noncoding human Y RNAs are overexpressed in tumours and required for cell proliferation. Br. J. Cancer 98(5), 981-988 (2008).

40 Dang CV. MYC on the path to cancer. Cell 149(1), 22-35 (2012).

41 Gomez-Roman N, Grandori C, Eisenman RN, White RJ. Direct activation of RNA polymerase III transcription by c-Myc. Nature 421(6920), 290-294 (2003).

42 Lin CY, Loven J, Rahl PB et al. Transcriptional amplification in tumor cells with elevated c-Myc. Cell 151(1), 56-67 (2012).

43 Sherr CJ, Mccormick F. The RB and $\mathrm{p} 53$ pathways in cancer. Cancer Cell 2(2), 103-112 (2002).

44 Larminie CG, Cairns CA, Mital R et al. Mechanistic analysis of RNA polymerase III regulation by the retinoblastoma protein. EMBO J. 16(8), 2061-2071 (1997).

45 Scott PH, Cairns CA, Sutcliffe JE et al. Regulation of RNA polymerase III transcription during cell cycle entry. J. Biol. Chem. 276(2), 1005-1014 (2001).

46 Cairns CA, White RJ. p53 is a general repressor of RNA polymerase III transcription. EMBO J. 17(11), 3112-3123 (1998).

47 Crighton D, Woiwode A, Zhang C et al. p53 represses RNA polymerase III transcription by targeting TBP and inhibiting promoter occupancy by TFIIIB. EMBO J. 22(11), 2810-2820 (2003).

48 Saitsu H, Osaka H, Sasaki M et al. Mutations in POLR3A and POLR3B encoding RNA Polymerase III subunits cause an autosomal-recessive hypomyelinating leukoencephalopathy. Am. J. Hum. Genet. 89(5), 644-651 (2011).

49 Bernard G, Chouery E, Putorti ML et al. Mutations of POLR3A encoding a catalytic subunit of RNA polymerase Pol III cause a recessive hypomyelinating leukodystrophy. Am. J. Hum. Genet. 89(3), 415-423 (2011).

50 Tetreault M, Choquet K, Orcesi $S$ et al. Recessive mutations in POLR3B, encoding the second largest subunit of Pol III, cause a rare hypomyelinating leukodystrophy. Am. J. Hum. Genet. 89(5), 652-655 (2011).

51 Thiffault I, Wolf NI, Forget D et al. Recessive mutations in POLR1C cause a leukodystrophy by impairing biogenesis of RNA polymerase III. Nat. Commun. 6, 7623 (2015).

52 Borck G, Hog F, Dentici ML et al. BRF1 mutations alter RNA polymerase III-dependent transcription and cause neurodevelopmental anomalies. Genome Res. 25(4), 609 (2015). 
53 Ishimura R, Nagy G, Dotu I et al. RNA function. Ribosome stalling induced by mutation of a CNS-specific tRNA causes neurodegeneration. Science 345(6195), 455-459 (2014).

54 Namavar Y, Barth PG, Poll-The BT, Baas F. Classification, diagnosis and potential mechanisms in pontocerebellar hypoplasia. Orphanet. J. Rare Dis. 6, 50 (2011).

55 Schaffer AE, Eggens VR, Caglayan AO et al. CLP1 founder mutation links tRNA splicing and maturation to cerebellar development and neurodegeneration. Cell 157(3), 651-663 (2014).

56 Karaca E, Weitzer S, Pehlivan D et al. Human CLP1 mutations alter tRNA biogenesis, affecting both peripheral and central nervous system function. Cell 157(3), 636-650 (2014).

57 Hanada T, Weitzer S, Mair B et al. CLP1 links tRNA metabolism to progressive motor-neuron loss. Nature 495(7442), 474-480 (2013).

58 Girotto G, Abdulhadi K, Buniello A et al. Linkage study and exome sequencing identify a $B D P 1$ mutation associated with hereditary hearing loss. PLoS ONE 8(12), e80323 (2013).

59 Ridanpaa M, Van Eenennaam H, Pelin K et al. Mutations in the RNA component of RNase MRP cause a pleiotropic human disease, cartilage-hair hypoplasia. Cell 104(2), 195-203 (2001).

60 Kumar Y, Bhargava P. A unique nucleosome arrangement, maintained actively by chromatin remodelers facilitates transcription of yeast tRNA genes. BMC Genomics 14, 402 (2013).

61 Li B, Carey M, Workman JL. The role of chromatin during transcription. Cell 128(4), 707-719 (2007).

62 Ridgway P, Almouzni G. Chromatin assembly and organization. J. Cell Sci. 114(Pt 15), 2711-2712 (2001).

63 Morse RH. Nucleosomes inhibit both transcriptional initiation and elongation by RNA polymerase III in vitro. EMBO J. 8(8), 2343-2351 (1989).

64 Tremethick D, Zucker K, Worcel A. The transcription complex of the 5 S RNA gene, but not transcription factor IIIA alone, prevents nucleosomal repression of transcription. J. Biol. Chem. 265(9), 5014-5023 (1990).

65 Felts SJ, Weil PA, Chalkley R. Transcription factor requirements for in vitro formation of transcriptionally competent 5S rRNA gene chromatin. Mol. Cell. Biol. 10(5), 2390-2401 (1990).

66 Englander EW, Wolffe AP, Howard BH. Nucleosome interactions with a human Alu element. Transcriptional repression and effects of template methylation. J. Biol. Chem. 268(26), 19565-19573 (1993).

67 Hansen JC, Wolffe AP. A role for histones H2A/H2B in chromatin folding and transcriptional repression. Proc. Natl Acad. Sci. USA 91(6), 2339-2343 (1994).

68 Bouvet P, Dimitrov S, Wolffe AP. Specific regulation of Xenopus chromosomal $5 \mathrm{~S}$ rRNA gene transcription in vivo by histone H1. Genes Dev. 8(10), 1147-1159 (1994).

69 Wolffe AP. Dominant and specific repression of Xenopus oocyte 5S RNA genes and satellite I DNA by histone $\mathrm{H} 1$. EMBO J. 8(2), 527-537 (1989).
70 Schlissel MS, Brown DD. The transcriptional regulation of Xenopus 5s RNA genes in chromatin: the roles of active stable transcription complexes and histone H1. Cell 37(3), 903-913 (1984).

71 Kandolf $\mathrm{H}$. The $\mathrm{H} 1 \mathrm{~A}$ histone variant is an in vivo repressor of oocyte-type $5 \mathrm{~S}$ gene transcription in Xenopus laevis embryos. Proc. Natl Acad. Sci. USA 91(15), 7257-7261 (1994).

72 Tomaszewski R, Mogielnicka E, Jerzmanowski A. Both the $5 \mathrm{~S}$ rRNA gene and the AT-rich flanks of xenopus laevis oocyte-type $5 \mathrm{~S}$ rDNA repeat are required for histone H1dependent repression of transcription of pol III-type genes in in vitro reconstituted chromatin. Nucleic Acids Res. 26(24), 5596-5601 (1998).

73 Chipev CC, Wolffe AP. Chromosomal organization of Xenopus laevis oocyte and somatic $5 \mathrm{~S}$ rRNA genes in vivo. Mol. Cell. Biol. 12(1), 45-55 (1992).

74 Howe L, Itoh T, Katagiri C, Ausio J. Histone H1 binding does not inhibit transcription of nucleosomal Xenopus laevis somatic 5 S rRNA templates. Biochemistry 37(20), 7077-7082 (1998).

75 Howe L, Ranalli TA, Allis CD, Ausio J. Transcriptionally active Xenopus laevis somatic $5 \mathrm{~S}$ ribosomal RNA genes are packaged with hyperacetylated histone $\mathrm{H} 4$, whereas transcriptionally silent oocyte genes are not. J. Biol. Chem. 273(33), 20693-20696 (1998).

76 Russanova VR, Driscoll CT, Howard BH. Adenovirus type 2 preferentially stimulates polymerase III transcription of Alu elements by relieving repression: a potential role for chromatin. Mol. Cell. Biol. 15(8), 4282-4290 (1995).

77 Morse RH, Roth SY, Simpson RT. A transcriptionally active tRNA gene interferes with nucleosome positioning in vivo. Mol. Cell. Biol. 12(9), 4015-4025 (1992).

78 Burnol AF, Margottin F, Huet J et al. TFIIIC relieves repression of U6 snRNA transcription by chromatin. Nature 362(6419), 475-477 (1993).

- Provides the clue to the importance of TFIIIC in chromatin remodeling.

79 Shivaswamy S, Kassavetis GA, Bhargava P. High-level activation of transcription of the yeast U6 snRNA gene in chromatin by the basal RNA polymerase III transcription factor TFIIIC. Mol. Cell. Biol. 24(9), 3596-3606 (2004).

80 Shivaswamy S, Bhargava P. Positioned nucleosomes due to sequential remodeling of the yeast U6 small nuclear RNA chromatin are essential for its transcriptional activation. J. Biol. Chem. 281(15), 10461-10472 (2006).

81 Arimbasseri AG, Bhargava P. Chromatin structure and expression of a gene transcribed by RNA polymerase III are independent of H2A.Z deposition. Mol. Cell. Biol. 28(8), 2598-2607 (2008).

82 Raab JR, Kamakaka RT. Insulators and promoters: closer than we think. Nat. Rev. Genet. 11(6), 439-446 (2010).

83 Isogai Y, Takada S, Tjian R, Keles S. Novel TRF1/BRF target genes revealed by genome-wide analysis of Drosophila Pol III transcription. EMBO J. 26(1), 79-89 (2007).

84 Noma K, Cam HP, Maraia RJ, Grewal SI. A role for TFIIIC transcription factor complex in genome organization. Cell 125(5), 859-872 (2006). 
85 Eberharter A, Becker PB. Histone acetylation: a switch between repressive and permissive chromatin. Second in review series on chromatin dynamics. EMBO Rep. 3(3), 224-229 (2002).

86 Ura K, Kurumizaka H, Dimitrov S, Almouzni G, Wolffe AP. Histone acetylation: influence on transcription, nucleosome mobility and positioning, and linker histone-dependent transcriptional repression. EMBO J. 16(8), 2096-2107 (1997). Lee DY, Hayes JJ, Pruss D, Wolffe AP. A positive role for histone acetylation in transcription factor access to nucleosomal DNA. Cell 72(1), 73-84 (1993).

Com Ramsbottom BA, Gomez-Roman N, Marshall L, Cole PA, White RJ. TRRAP and GCN5 are used by c-Myc to activate RNA polymerase III transcription. Proc. Natl Acad. Sci. USA 104(38), 14917-14922 (2007).

- A mechanistic study about histone acetylation and Pol III transcription.

89 Tse C, Sera T, Wolffe AP, Hansen JC. Disruption of higher-order folding by core histone acetylation dramatically enhances transcription of nucleosomal arrays by RNA polymerase III. Mol. Cell. Biol. 18(8), 4629-4638 (1998).

90 Hsieh YJ, Kundu TK, Wang Z, Kovelman R, Roeder RG. The TFIIIC90 subunit of TFIIIC interacts with multiple components of the RNA polymerase III machinery and contains a histone-specific acetyltransferase activity. Mol. Cell. Biol. 19(11), 7697-7704 (1999).

91 Kundu TK, Wang Z, Roeder RG. Human TFIIIC relieves chromatin-mediated repression of RNA polymerase III transcription and contains an intrinsic histone acetyltransferase activity. Mol. Cell. Biol. 19(2), 1605-1615 (1999).

92 Mertens C, Roeder RG. Different functional modes of p300 in activation of RNA polymerase III transcription from chromatin templates. Mol. Cell. Biol. 28(18), 5764-5776 (2008).

93 Ravens S, Yu C, Ye T, Stierle M, Tora L. Tip60 complex binds to active Pol II promoters and a subset of enhancers and co-regulates the c-Myc network in mouse embryonic stem cells. Epigenetics Chromatin 8, 45 (2015).

94 Jin Q, Yu LR, Wang L et al. Distinct roles of GCN5/PCAFmediated $\mathrm{H} 3 \mathrm{~K} 9 \mathrm{ac}$ and $\mathrm{CBP} / \mathrm{p} 300$-mediated $\mathrm{H} 3 \mathrm{~K} 18 / 27 \mathrm{ac}$ in nuclear receptor transactivation. EMBO J. 30(2), 249-262 (2011)

95 Mikkelsen TS, Ku M, Jaffe DB et al. Genome-wide maps of chromatin state in pluripotent and lineage-committed cells. Nature 448(7153), 553-560 (2007).

96 Wang Z, Zang C, Rosenfeld JA et al. Combinatorial patterns of histone acetylations and methylations in the human genome. Nat. Genet. 40(7), 897-903 (2008).

97 Li J, Moazed D, Gygi SP. Association of the histone methyltransferase Set2 with RNA polymerase II plays a role in transcription elongation. J. Biol. Chem. 277(51), 49383-49388 (2002).

98 Liu C, Li S, Dai X et al. PRC2 regulates RNA polymerase III transcribed non-translated RNA gene transcription through EZH2 and SUZ12 interaction with TFIIIC complex. Nucleic Acids Res. 43(13), 6270-6284 (2015).

- A mechanistic study about histone methylation and Pol III transcription.
99 Rossetto D, Avvakumov N, Cote J. Histone phosphorylation: a chromatin modification involved in diverse nuclear events. Epigenetics 7(10), 1098-1108 (2012).

100 Zhang Q, Zhong Q, Evans AG, Levy D, Zhong S. Phosphorylation of histone $\mathrm{H} 3$ serine 28 modulates RNA polymerase III-dependent transcription. Oncogene 30 (37), 3943-3952 (2011).

101 Zhong Q, Shi G, Zhang Q, Zhang Y, Levy D, Zhong S. Role of phosphorylated histone $\mathrm{H} 3$ serine 10 in DEN-induced deregulation of Pol III genes and cell proliferation and transformation. Carcinogenesis 34(11), 2460-2469 (2013).

102 Listerman I, Bledau AS, Grishina I, Neugebauer KM. Extragenic accumulation of RNA polymerase II enhances transcription by RNA polymerase III. PLoS Genet. 3(11), e212 (2007).

103 Antequera F. Structure, function and evolution of $\mathrm{CpG}$ island promoters. Cell. Mol. Life Sci. 60(8), 1647-1658 (2003).

104 Besser D, Gotz F, Schulze-Forster K, Wagner H, Kroger H, Simon D. DNA methylation inhibits transcription by RNA polymerase III of a tRNA gene, but not of a $5 \mathrm{~S}$ rRNA gene. FEBS Lett. 269(2), 358-362 (1990).

105 Juttermann R, Hosokawa K, Kochanek S, Doerfler W. Adenovirus type 2 VAI RNA transcription by polymerase III is blocked by sequence-specific methylation. J. Virol. 65(4), 1735-1742 (1991).

106 Banati F, Koroknai A, Salamon D et al. CpG-methylation silences the activity of the RNA polymerase III transcribed EBER-1 promoter of Epstein-Barr virus. FEBS Lett. 582(5), 705-709 (2008).

107 Liu WM, Schmid CW. Proposed roles for DNA methylation in Alu transcriptional repression and mutational inactivation. Nucleic Acids Res. 21(6), 1351-1359 (1993).

108 Selvakumar T, Gjidoda A, Hovde SL, Henry RW. Regulation of human RNA polymerase III transcription by DNMT1 and DNMT3a DNA methyltransferases. J. Biol. Chem. 287(10), 7039-7050 (2012).

109 Bartke T, Vermeulen M, Xhemalce B, Robson SC, Mann M, Kouzarides T. Nucleosome-interacting proteins regulated by DNA and histone methylation. Cell 143(3), 470-484 (2010).

110 Garcia MA, Meurs EF, Esteban M. The dsRNA protein kinase PKR: virus and cell control. Biochimie 89(6-7), 799-811 (2007).

111 Lee YS. A novel type of non-coding RNA, nc886, implicated in tumor sensing and suppression. Genomics Inform. 13(2), 26-30 (2015).

112 Romanelli V, Nakabayashi K, Vizoso M et al. Variable maternal methylation overlapping the nc886/vtRNA2-1 locus is locked between hypermethylated repeats and is frequently altered in cancer. Epigenetics 9(5), 783-790 (2014).

113 Silver MJ, Kessler NJ, Hennig BJ et al. Independent genomewide screens identify the tumor suppressor VTRNA2-1 as a human epiallele responsive to periconceptional environment. Genome Biol. 16(1), 118 (2015). 